\title{
Perception of Physicians to the Role of Clinical Pharmacists in United Arab Emirates (UAE)
}

\author{
Osama Mohamed Ibrahim ${ }^{1,2}$, Rana Ibrahim1 \\ ${ }^{1}$ Department of Pharmacy Practice and Pharmacotherapeutics, College of Pharmacy, University of Sharjah, \\ Sharjah, United Arab Emirates \\ ${ }^{2}$ Department of Clinical Pharmacy, Faculty of Pharmacy, Cairo University, Cairo, Egypt \\ Email: oibrahim@sharjah.ac.ae
}

Received 24 June 2014; revised 25 July 2014; accepted 13 August 2014

Copyright (C) 2014 by authors and Scientific Research Publishing Inc.

This work is licensed under the Creative Commons Attribution International License (CC BY).

http://creativecommons.org/licenses/by/4.0/

c) (i) Open Access

\section{Abstract}

The present study aims to investigate the perceptions and experience of physicians regarding the clinical role of the pharmacists. This is an observational study that was conducted during the period of September 2013 through March 2014. A self-administered questionnaire was designed to be distributed by personal interview to the physicians. The questionnaire population consisted of randomly selected physicians practicing in UAE. The questionnaire was piloted by 10 physicians for face and understandability. Demographic data, frequencies and cross tabulation between different variables were calculated. The Chi-square test was used to determine the significance of association between categorical variables (gender, length of medical practice, and specialty) and the perception of physicians. A total of 285 filled questionnaires were returned representing 285 physicians, with a male dominance $(65.3 \%)$. The average age of the physician screened was 32.4 $(S D=10.38)$ years with a minimum one year experience and up to 24 years. General practitioners consumed the widest sector $(21.8 \%)$ followed by cardiologists $(15.8 \%)$, then internal medicine (10.1\%). In the current study, two thirds of the physicians believed that pharmacists could act as a reliable source of general drug information and play an important role in discovering clinical related problems. It was found that the physicians who had fewer years in practice (less than 10 years) and recently graduated had more acceptances to the clinical role of the pharmacist and believed that there should be a clinical pharmacy services in their hospitals (p-value $<0.05$ ). No other statistically significant differences were found from analyzing the data. In conclusion, results suggest that physicians in UAE appear comfortable with pharmacists providing the broad range of services but appear somewhat less comfortable with pharmacists' provision of direct patient care.

\section{Keywords}

Clinical Pharmacists, Physicians, Perception, Questionnaire, United Arab Emirates 


\section{Introduction}

For centuries, the physician is known as the person who diagnoses the disease and writes the prescription while the pharmacist is the person who compounds and dispenses these prescriptions [1] [2]. Nowadays, clinical pharmacy is a health science discipline whereby pharmacists provide patient care that optimizes medication therapy and promotes health, wellness, and disease prevention. This field of pharmacy practice focuses on patient-oriented rather than drug product-oriented service [3]. The science of clinical pharmacy arose out of dissatisfaction of pharmacists with old practice and the increasing need for a competent health professional with a comprehensive knowledge in the pharmacotherapy field. The addition of clinical pharmacy services to the care of inpatients generally results in improved patient care because clinical pharmacists are a primary source of scientifically valid information and advice regarding the safe, appropriate, and cost-effective use of medications [4]-[6].

There has been a relatively long tradition of clinical activities being performed by pharmacists working within the hospital setting around the world [7]. In UAE, although the traditional model of the pharmacist is still serving, the role of pharmacists is changing in a trial to keep pace with the advanced needs of healthcare system. Pharmacists working in UAE recognize the need to assume a role in the safe and rational use of medicines and are willing to receive this responsibility to ensure maximum benefit for the patients.

In the developed world, professional relationship between the physicians and the pharmacists can be described as ideal professional relationship [8]. The level of interaction between them in developed countries is high, resulting in safer, more effective, and less costly drug therapy [4]. On the other hand, in developing countries like UAE, the pharmacy profession is still facing several barriers, among which are shortage of qualified pharmacists, the lack of standard practice guidelines [9] and the physicians and pharmacists often are seen as opponents rather than members of the same team [2]. Physicians in UAE may not always be aware of how pharmacists function or recognize how they assure safe medication use.

\section{Objective}

The present study aims to investigate the perceptions and experience of physicians regarding the clinical role of the pharmacists, their acceptance of new pharmacist roles and the extent of collaboration that can occur.

\section{Methodology}

This is an observational study, which used a specially designed survey to determine the role of clinical pharmacists as perceived by the physicians working in United Arab Emirates. A self-administered questionnaire was designed to be distributed by personal interview to the physicians who would require approximately 15 minutes to complete the questionnaire. The survey population consisted of randomly selected physicians from Sharjah, Dubai and Ajman Emirates. The questionnaire is composed of 17 questions both close-ended and open-ended questions. The questions covered two domains: physicians' demographic data, the perception of the physician about the role of the traditional pharmacists, and the perception of the physician about the role of clinical pharmacists. The questionnaire was piloted by 10 physicians for face and understandability. All the feedback from the pilot physicians were taken in consideration when designing the final version of the questionnaire. The study was conducted during the period of September 2013 through March 2014.

Demographic data frequencies and cross tabulation between different variables were calculated. The Chisquare test was used to determine the significance of association between categorical variables (gender, length of medical practice, and specialty). Descriptive statistics and Chi-square tests were calculated using SPSS for Windows standard version release 16.0 .

\section{Results}

A total of 285 filled questionnaires were returned representing 285 physicians, with a male dominance (65.3\%). The average age of the physician screened was $32.4(\mathrm{SD}=10.38)$ years with a minimum one year experience and up to 24 years.

Physicians were randomly selected from different governmental hospitals, private hospitals, private clinics, and health centers. More than half (56\%) of the recruited physicians were staff members in private clinics and health centers (Figure 1). 


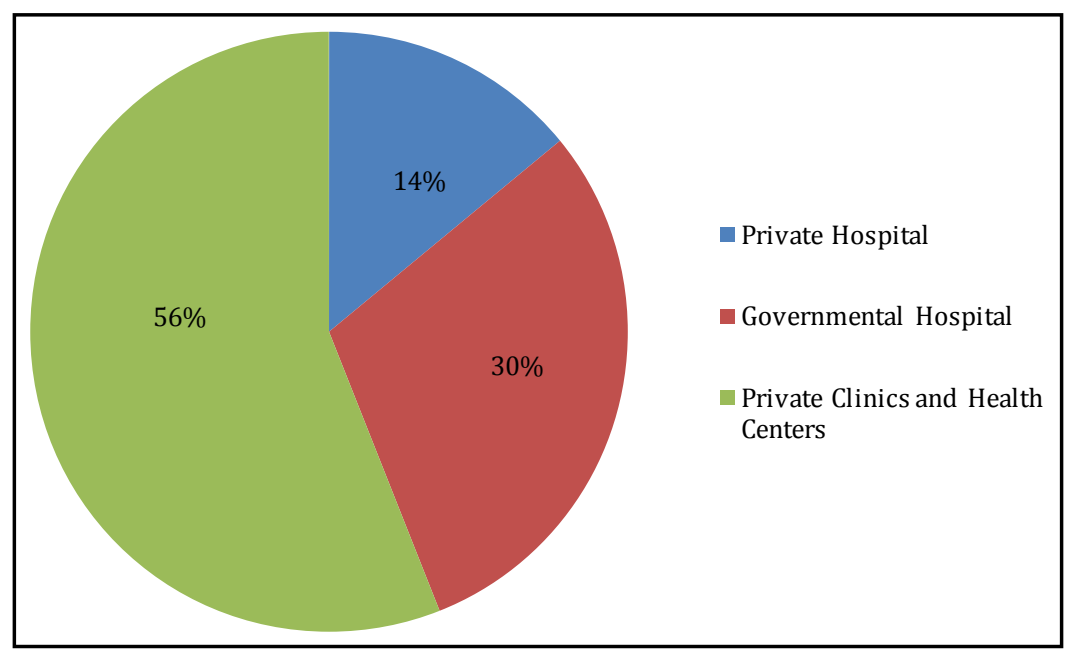

Figure 1. Percentage of distribution of the locations from which the physicians were recruited.

When it comes to the specialty of the recruited physicians, it can be easily observed from Table 1 that, almost all known specialties were represented in this survey. General practitioners consumed the widest sector (21.8\%) followed by cardiologists (15.8\%), then internal medicine (10.1\%).

Most of the doctors admitted that they have some form of contact with the pharmacists. The rate of contact varied from once a day down to once a week. When we analyzed the nature of this contact it was found that, using the pharmacist as a source of information about the medications (side effects, drug interactions, pregnancy category or efficacy) was the main role of the pharmacist as believed by the physicians. Moreover, $43 \%$ of the physicians admitted that pharmacists are already a source of identification of medication related problems.

In the current study, two thirds of the physicians believed that pharmacists can act as a reliable source of general drug information while only about $25 \%$ of the screened population believed that, pharmacists can be a reliable source of clinical information, and medication cost effectiveness. The perception of the physicians for the traditional role(s) of the pharmacists is shown in Table 2.

Although more than $80 \%$ of the screened hospitals did not have clinical pharmacy services there, about $90 \%$ of the screened physicians declared their awareness about the clinical pharmacy concept. According to what was mentioned by the screened physicians, identification of drug related problems including drug-drug interactions, adverse events and contraindications, together with cost related information were the main roles of the clinical pharmacists (Table 3).

Expectations of the physicians of clinical pharmacists' responsibilities in healthcare settings are shown in Figure 2. Majority of healthcare providers were expecting that clinical pharmacists should play a crucial role in minimizing medications errors and providing patient counseling, and identified them as members in the healthcare team to improve the quality of service.

There was a high level of agreement (more than 74\%) that, physicians and clinical pharmacists should have daily cooperation, where Phone calls was selected to be the best method of communication between them (Figure 3).

When different results were stratified according to age, gender, site of practice and years of practice, it was found that there is a statistically significant difference in accepting the clinical role of pharmacists between physicians who have more than ten years in practice and physicians who have less than 10 years in practice (p-value $<0.05$ ). It was found that the physicians who have fewer years in practice and recently graduated have more acceptances to the clinical role of the pharmacist and believe that there should be a clinical pharmacy services in their hospitals. No other statistically significant differences were found from analyzing the data.

\section{Discussion}

Resolution of a medication related problem needs coordination and collaboration between different healthcare professions within an interdisciplinary team. This requires expanding the role of the pharmacist within the 
healthcare profession and providing pharmaceutical care. This role expansion for pharmacists has not necessarily been a comfortable change for all the health care professionals [10] [11].

Table 1. Demographic parameters of the recruited physicians.

\begin{tabular}{lc}
\hline Parameter & Value \\
\hline Average age in years (SD) & $32.4(10.38)$ \\
Average years of experience (SD) & $15.7(8.62)$ \\
Male (\%) & $186(65.3)$ \\
Qualifications of screen physicians (\%) & \\
B.Sc. & $65(22.8)$ \\
M.Sc. & $157(55)$ \\
MD/Ph.D. & $63(22.2)$ \\
Screened specialties (\%) & \\
Cardiology & $45(15.8)$ \\
General practitioner & $62(21.8)$ \\
Pediatrics & $26(9.1)$ \\
Internal medicine & $29(10.1)$ \\
Intensive care & $24(8.4)$ \\
Orthopedics & $35(12.3)$ \\
ENT & $23(8.1)$ \\
Gastroenterology & $25(8.8)$ \\
Urology & $16(5.6)$ \\
\hline
\end{tabular}

SD: standard deviation; B.Sc.: bachelor of science; M.Sc.: master of science; MD: doctor of medicine; Ph.D.: doctor of philosophy; ENT: ear, nose and throat.

\section{Table 2. Perception of the physicians for the traditional role(s) of the pharmacists.}

\begin{tabular}{cc}
\hline Role of the pharmacist as perceived by the physicians & Frequency (\%) \\
\hline Purchasing and dispensing medication & $19(6.7)$ \\
Drug information & $34(11.8)$ \\
Advise about alternatives & $11(3.8)$ \\
Dose adjusting & $19(6.7)$ \\
Providing information about drug interaction & $16(5.6)$ \\
Providing information about side effects & $18(6.3)$ \\
Medication review & $5(1.8)$ \\
Participate in clinical round & $8(2.8)$ \\
Cooperation with the physician & $9(3.2)$ \\
Teaching & $8(2.8)$ \\
Formulation and preparation of IV and chemotherapy & $18(6.3)$ \\
Medication marketing and promotion & $17(6)$ \\
Providing information about dosage regimen & $6(2.1)$ \\
Advise about medication availability & $25(8.8)$ \\
Quality, auditing and reporting and meetings & $6(2.1)$ \\
Providing information about drug name & $8(2.8)$ \\
Providing information about drug efficacy & $19(6.7)$ \\
Providing information about the cost of the medication & $21(7.4)$ \\
Drug selection & $6(2.1)$ \\
Assess compliance & $12(4.2)$ \\
Total & 285 \\
\hline
\end{tabular}


Table 3. Role of the clinical pharmacist from the physician's point of view.

\begin{tabular}{cc}
\hline The role of the clinical pharmacists & Frequency (\%) \\
N $=285$
\end{tabular}

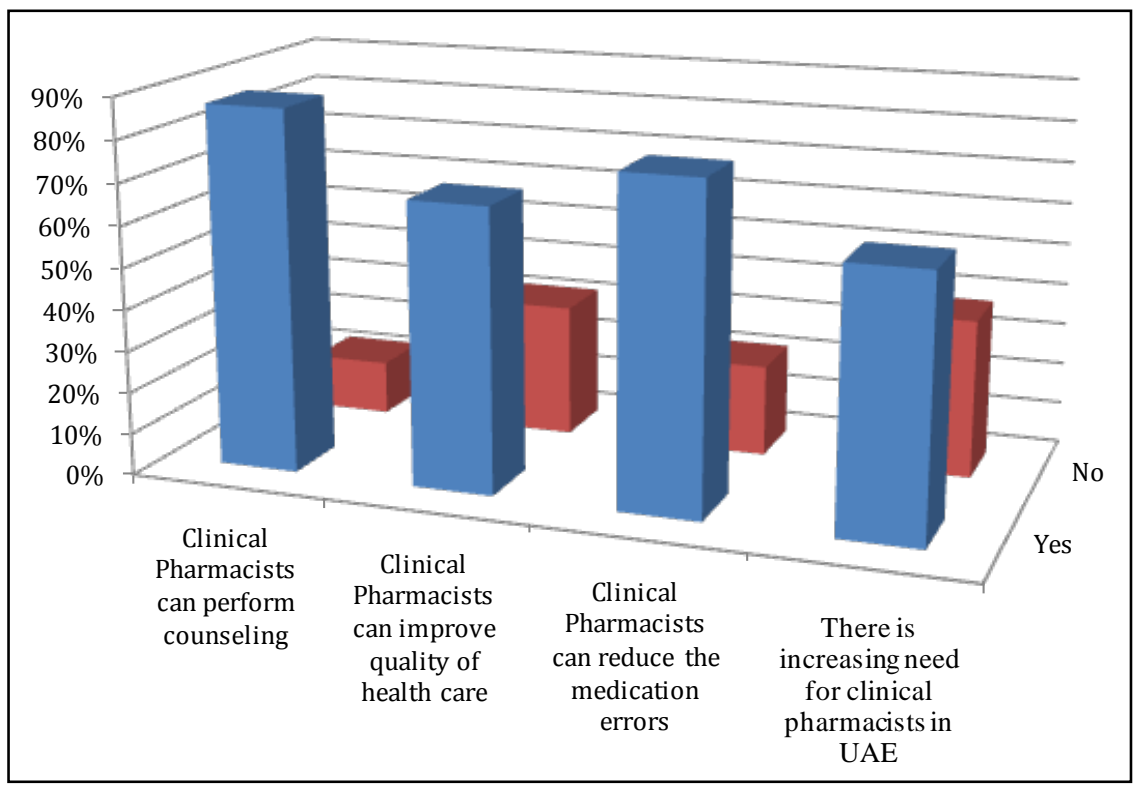

Figure 2. Expectations of the UAE physicians from clinical pharmacists.

Although there are several definitions of the concept of the pharmaceutical care, most agree that, a pharmacist's commitment to the patient is to attain the patient's health objectives. This concept has become greatly used in USA, Canada, but it has received less recognition in Europe with the exception of the United Kingdom and the Netherlands [12]. Together with the growing concept of pharmaceutical care, the clinical role of pharmacists was budding in countries with more developed pharmacy systems, as in Japan, Nigeria, and Sweden [12]-[15]. 


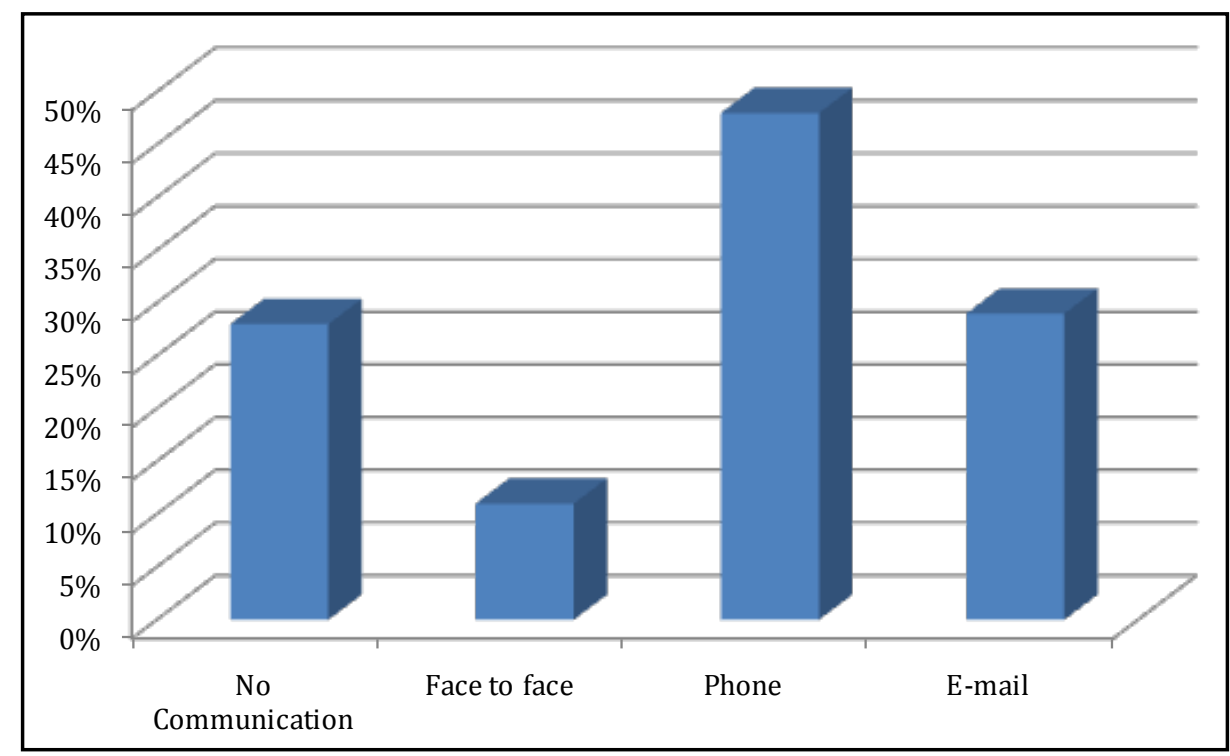

Figure 3. Methods of communications between physicians and clinical pharmacists as perceived by the physicians.

Researches have shown that, clinical pharmacists have a significant impact on patient safety in intensive care units, inpatient wards and emergency department (ED) [16]-[19], but few hospitals in UAE utilize dedicated clinical pharmacists.UAE health authorities have sought to implement pharmaceutical care services within the country healthcare system in order to improve patients' quality of life and ensure rational use of medicines. Successful implementation of pharmaceutical care requires cooperation between clinical pharmacists and other healthcare professionals. Increased interaction between pharmacists and physicians in the developed countries managed to produce more effective, safer and less costly drug therapy [19] [20].

Pharmacists in the UAE society are mainly seen as medication sellers who do not have independent thinking. Some colleges of pharmacy in UAE do not fulfill the minimal requirements for an appropriate education in clinical pharmacy. They are still largely focused on old model of pharmacy activity, e.g., based on chemistry and basic sciences knowledge. Few universities have modified and broadened their curriculum including topics as epidemiology, pharmacotherapy, clinical pharmacokinetics and communication skills, the latter being particularly important for community pharmacists.

Although most published studies of perceptions of physicians towards pharmacy profession evolved from countries where forward-moving patient oriented pharmacy practice have been advancing for decades, few surveys have been reported in the middle-east region like Kuwait, Jordan, Sudan, and Egypt [21]-[25].

In UAE, and according to the present questionnaire, physicians appeared familiar with role of the traditional roles of pharmacists, including dispensing, purchasing and information providers. Although the nature of Emirati society gives the pharmacist the chance to prescribe medications for both minor and major ailments, only few physicians admitted this fact. This finding supports a number of previous studies, which showed that physicians are reluctant to accept pharmacist roles, which include any aspects of prescribing [23] [25]-[28].

The perception of the physicians in UAE about specific clinical pharmacists roles showed mixed responsesrangingfromveryfavorableacceptancetowardspharmacistsreportingadversedrugreactions, dose adjusting, increasingtheirroleinadvisingphysiciansaboutcosteffectiveprescribing and medication selection according to effectiveness and safety, tounfavorable acceptance for clinical pharmacists in UAE society with reasoning that, the society is not ready for such profession. Such an unfavorable attitude may be attributed to the lack of physician exposure to pharmacists participating in different clinical pharmacy activities. In UK similar perceptions were reported 20 years ago [26].

It is clear from this observational study that physicians experienced misconception between the role of traditional pharmacist and that of clinical pharmacist where there was a major overlap between what was mentioned by doctors to describe the first concept and the second. On the other hand, the study revealed that physicians working in UAE appear to have high expectations of pharmacists as knowledgeable drug therapy experts and 
expect them to educate patients about the safe and appropriate use of medications. Kuwaiti and Egyptian physicians reported similar expectations [23] [25].

Only few doctors agreed that patient medication counseling is one of the core services that should be provided by clinical pharmacists. Higher percentages were reported in studies carried out in Sudan and Pakistan [23] [29].

A significant trend was observed between years of experience of the physicians and their acceptance of the role of clinical pharmacists. Similar results were detected in USA where younger American physicians have expressed higher expectations of pharmacy practice and collaboration when compared to senior colleagues [19].

\section{Limitation}

The present study has some limitations. First of all the study has relatively small sample size. Second, parallel exploring study about the pharmacist training and competency was not conducted. It is possible that skills and confidence in pharmacists' competency account for reduced acceptance and expectations of physicians for clinical pharmacy activities.

\section{Conclusion}

This study suggests that physicians in UAE appear comfortable with pharmacists providing the broad range of services but appear somewhat less comfortable with pharmacists' provision of direct patient care. Physicians considered pharmacists knowledgeable drug therapy experts but closer cooperation and better communication might help improve the quality of service provided to patients. Greater effort needs to be directed toward increasing physician awareness about the importance of collaboration with clinical pharmacist and what benefits can be reflected from this on patient's quality of life and health care efficiency.

\section{Conflict of Interest}

The authors declare no conflict of interest.

\section{References}

[1] Kaboli, P.J., Hoth, A.B., McClimon, B.J. and Schnipper, J.L. (2006) Clinical Pharmacists and Inpatient Medical Care: A Systematic Review. Archives of Internal Medicine, 166, 955-964. http://dx.doi.org/10.1001/archinte.166.9.955

[2] Ma, C., Holuby, S. and Bucci, L. (2010) Physician and Pharmacist Collaboration: The University of Hawai'i at Hilo College of Pharmacy_JABSOM Experience. Hawaii Medical Journal, 69, 42-44.

[3] American College of Clinical Pharmacy (2008) The Definition of Clinical Pharmacy. Pharmacotherapy, 28, 816-817. http://dx.doi.org/10.1592/phco.28.6.816

[4] Barker, K.N. and Valentino, J.G. (1972) On a Political and Legal Foundation for Clinical Pharmacy Practice. Journal of American Pharmacists Association, 12, 202-206.

[5] Leape, L.L., Cullen, D.J., Clapp, M.D., Burdick, E., Demonaco, H.J., Erickson, J.I. and Bates, D.W. (1999) Pharmacist Participation on Physician Rounds and Adverse Drug Events in the Intensive Care Unit. JAMA, 282, 267-270. http://dx.doi.org/10.1001/jama.282.3.267

[6] Bond, C.A., Raehl, C.L. and Franke, T. (2002) Clinical Pharmacist Staffing in United States Hospitals. Pharmacotherapy, 22, 1489-1499. http://dx.doi.org/10.1592/phco.22.16.1489.33689

[7] Gowen, D.L. (1992) Changing Relationship between Pharmacists and Physicians. American Journal of Hospital Pharmacy, 49, 2715-2721.

[8] Bosma, L., Jansman, F.G., Franken, A.M., Hartig, J.W. and Van den Bemt, P.M. (2008) Evaluation of Pharmacist Clinical Interventions in a Dutch Hospital Setting. Pharmacy World and Science, 30, 31-38. http://dx.doi.org/10.1007/s11096-007-9136-9

[9] Adepu, R. and Nagavi, B.J. (2006) General Practitioners Perception about the Extended Role of the Community Pharmacist in the State of Kamataka: A Study. Indian Journal of Pharmaceutical Sciences, 68, 36-40. http://dx.doi.org/10.4103/0250-474X.22961

[10] Sing, W.S. (2001) Pharmacy Practice in Malaysia. Malaysian Journal of Pharmaceutical Sciences, 1, 3-9.

[11] Hughes, C.M., Hawwa, A.F., Scullin, C., Anderson, C., Bernsten, C.B., Björnsdóttir, I., Cordina, M.A., da Costa, F.A., De Wulf, I., Eichenberger, P., Foulon, V., Henman, M.C., Hersberger, K.E., Schaefer, M.A., Søndergaard, B., Tully, M.P., Westerlund, T. and McElnay, J.C. (2010) Provision of Pharmaceutical Care by Community Pharmacists: A 
Comparison across Europe. Pharmacy World and Science, 32, 472-487. http://dx.doi.org/10.1007/s11096-010-9393-x

[12] Van Mil, J.W. (2005) Pharmaceutical Care in Community Pharmacy: Practice and Research in the Netherlands. Annals of Pharmacotherapy, 39, 1720-1725. http://dx.doi.org/10.1345/aph.1G141

[13] Ikeda, H. (2007) Practice of Pharmaceutical Care. Yakugaku Zasshi, 127, 1441-1448. http://dx.doi.org/10.1248/yakushi.127.1441

[14] Hirotani, Y. (2007) Proceedings of Clinical Pharmacy Research by the Cooperation with Community and Hospital Pharmacist and Pharmacy School. Yakugaku Zasshi, 127, 1801-1804. http://dx.doi.org/10.1248/yakushi.127.1801

[15] Aguwa, C.N., Ukwe, C.V. and Ekwunife, O.I. (2007) Effect of Pharmaceutical Care Programme on Blood Pressure and Quality of Life in a Nigerian Pharmacy. Pharmacy World and Science, 30, 107-110. http://dx.doi.org/10.1007/s11096-007-9151-x

[16] Leape, L.L., Cullen, D.J., Clapp, M.D., Burdick, E., Demonaco, H.J., Erickson, J.I. and Bates, D.W. (1999) Pharmacist Participation on Physician Roundsand Adverse Drug Events in the Intensive Care Unit. The Journal of the American Medical Association, 282, 267-270. http://dx.doi.org/10.1001/jama.282.3.267

[17] Kaushal, R., Bates, D.W., Landrigan, C., McKenna, K.J., Clapp, M.D., Federico, F. and Goldmann, D.A. (2001) Medication Errors and Adverse Drugevents in Pediatric Inpatients. The Journal of the American Medical Association, 285, 2114-2120. http://dx.doi.org/10.1001/jama.285.16.2114

[18] Kane, S.L., Weber, R.J. and Dasta, J.F. (2003) The Impact of Critical Care Pharmacists On Enhancing Patient Outcomes. Journal of Intensive Care Medicine, 29, 691-698.

[19] Ranelli, P.L. and Biss, J. (2000) Physician’s Perceptions of Communication with and Responsibilities of Pharmacists. The Journal of the American Medical Association, 40, 625-630.

[20] Martin, S. (1989) In the Physician’s Office: An Interview with W. Ray Burns. American Pharmacy, 29, 17-19.

[21] Mitchell, J.L. (1990) Building Cooperation with Physicians: An Interview with Charles Fortner. American Pharmacy, 30, 24-26.

[22] Matowe, L., Abahussain, E.A., Al-Saffar, N., Bihzad, S.M., Al-Foraih, A. and Al-Kandery, A.A. (2006) Physicians’ Perceptions and Expectations of Pharmacists’ Professional Duties in Government Hospitals in Kuwait. Medical Principles and Practice, 15, 185-189. http://dx.doi.org/10.1159/000092179

[23] Awad, A., Matowe, L. and Capps, P. (2007) Medical Doctors' Perceptions and Expectations of the Role Hospital Pharmacists in Sudan. Pharmacy World and Science, 29, 557-564. http://dx.doi.org/10.1007/s11096-007-9111-5

[24] Tahaineh, L., Wazaify, M., Albsoul-Younes, A., Khader, Y. and Zaidan, M. (2009) Perception Experiences, and Expectations of Physicians in Hospital Settings in Jordan Regarding the Role of the Pharmacist. Research in Social and Administrative Pharmacy, 5, 63-70. http://dx.doi.org/10.1016/j.sapharm.2008.05.003

[25] Sabry, N.A. and Farid, S.F. (2014) The Role of Clinical Pharmacists as Perceived by Egyptian Physicians. International Journal of Pharmacy Practice. http://dx.doi.org/10.1111/ijpp.12087

[26] Spencer, J.A. and Edwards, C. (1992) Pharmacy beyond the Dispensary: General Practitioners’ Views. British Medical Journal, 304, 1670-1672. http://dx.doi.org/10.1136/bmj.304.6843.1670

[27] Ritchey, F.J. and Raney, M.R. (1981) Effect of Exposure on Physicians’ Attitudes toward Clinical Pharmacists. American Journal of Hospital Pharmacy, 38, 1459-1463.

[28] Wilbur, K., Beniles, A. and Hammuda, A. (2012) Physician Perceptions of Pharmacist Roles in a Primary Care Setting in Qatar. Globalization and Health, 8, 12. http://dx.doi.org/10.1186/1744-8603-8-12

[29] Azhar, S., Hassali, M.A. and Ibrahim, M.M. (2010) Doctors' Perception and Expectations of the Role of the Pharmacist in Punjab, Pakistan. Tropical Journal of Pharmaceutical Research, 9, 205-222. http://dx.doi.org/10.4314/tjpr.v9i3.56279 
Scientific Research Publishing (SCIRP) is one of the largest Open Access journal publishers. It is currently publishing more than 200 open access, online, peer-reviewed journals covering a wide range of academic disciplines. SCIRP serves the worldwide academic communities and contributes to the progress and application of science with its publication.

Other selected journals from SCIRP are listed as below. Submit your manuscript to us via either submit@scirp.org or Online Submission Portal.
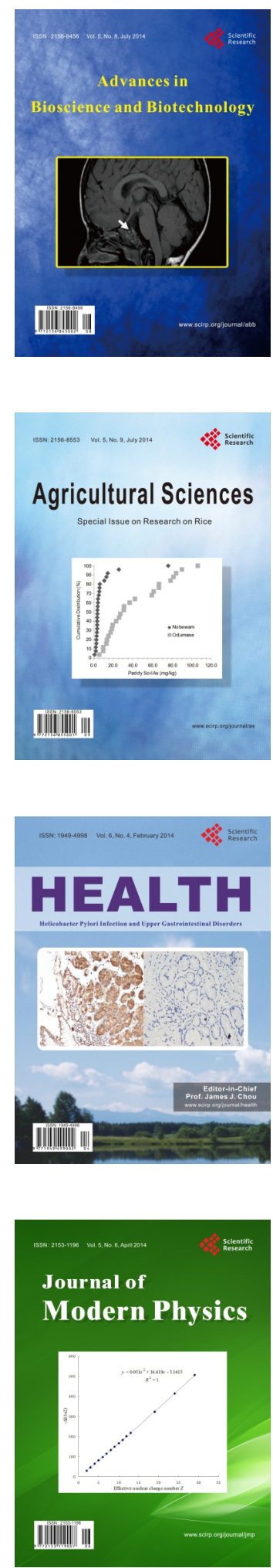
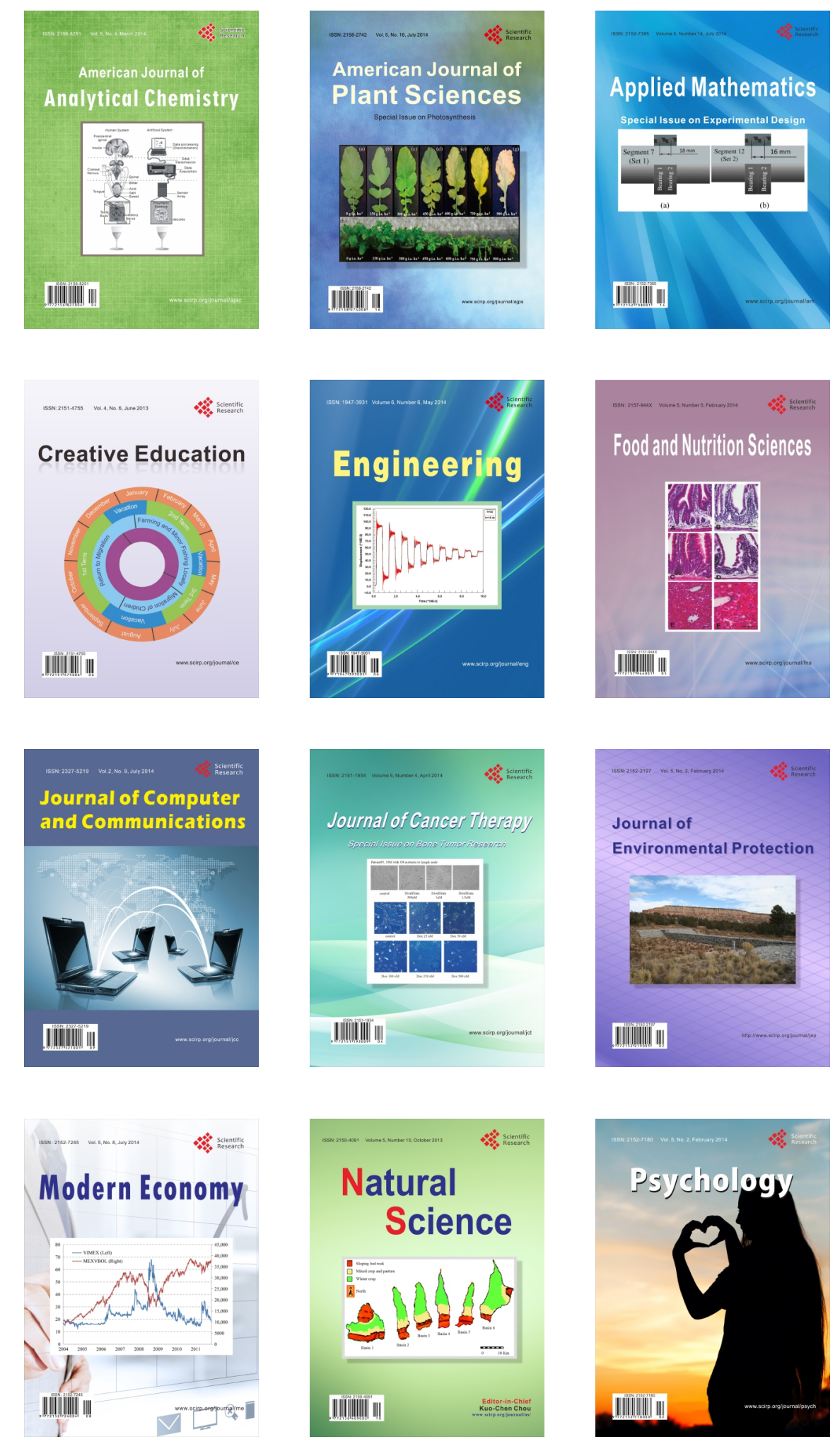